\title{
Prior smoking and nasoseptal flap usage adversely impact quality of life and healing after endoscopic pituitary surgery
}

\author{
Aryan Shay, BS, ${ }^{1}$ Morgan Sturgis, BS, ${ }^{1}$ Ethan M. Ritz, MS, ${ }^{2}$ Andre Beer-Furlan, MD, PhD, \\ Lorenzo Muñoz, MD,, ${ }^{3,4}$ Richard Byrne, MD,,3 Bobby A. Tajudeen, MD, ${ }^{3,5}$ and Pete S. Batra, MD ${ }^{3,5}$ \\ ${ }^{1}$ Rush Medical College, ${ }^{2}$ Rush Bioinformatics and Biostatistics Core, ${ }^{3}$ Rush Center for Skull Base and Pituitary Surgery, and \\ Departments of ${ }^{4}$ Neurosurgery and ${ }^{5}$ Otorhinolaryngology-Head and Neck Surgery, Rush University Medical Center, Chicago, \\ Illinois
}

OBJECTIVE Endoscopic pituitary surgery (EPS) via the endonasal transsphenoidal approach is well established as an effective treatment modality for sellar masses. The objective of this study was to determine the relationship between key patient and operative variables and rhinological outcomes as determined by the 22-item Sino-Nasal Outcome Test (SNOT-22) and endoscopic scores following EPS.

METHODS Prospectively collected SNOT-22 scores and objective endoscopic data were analyzed from a cohort of 109 patients who underwent EPS and had at least 90 days of postoperative follow-up. Trends in postoperative SNOT-22 scores were analyzed using linear mixed-effects models. Time to return to baseline endoscopic score was analyzed using Cox regression.

RESULTS After adjusting for age and sex, the authors found that prior smokers had higher total and rhinological subdomain SNOT-22 scores ( $p<0.01,95 \% \mathrm{Cl} 5.82-16.39$; $p=0.01,95 \% \mathrm{Cl} 1.38-5.09$, respectively) following EPS. Nasoseptal flap use also showed higher total and rhinological subdomain SNOT-22 scores $(p=0.01,95 \% \mathrm{Cl} 1.62-12.60 ; p=$ $0.02,95 \% \mathrm{Cl} 0.42-4.30$, respectively). Prior sinonasal surgery and concurrent septoplasty did not affect the change in SNOT-22 total scores over time $(p=0.08,95 \% \mathrm{Cl}-0.40$ to $0.02 ; p=0.33,95 \% \mathrm{Cl}-0.09$ to 0.29 ).

CONCLUSIONS The findings suggest that the evolution of healing and patient-reported quality of life (QOL) measures are multifaceted with contributions from two key variables. Nasoseptal flap usage and prior smoking status may adversely impact postoperative QOL. No variables were found to be associated with objective postoperative endoscopic findings. https://thejns.org/doi/abs/10.3171/2020.3.FOCUS2050

KEYWORDS quality of life; pituitary surgery; skull base surgery; SNOT-22; nasoseptal flap; smoking

$\mathrm{E}$ NDOSCOPIC pituitary surgery (EPS) via the endonasal transsphenoidal approach has become integral to the management of the majority of pituitary lesions. The use of EPS evolved from advancements in endoscopy and has been favored over open craniotomy or the sublabial approach in most clinical scenarios due to decreased morbidity and improved visualization. ${ }^{11,19}$ Current indications for transsphenoidal EPS include functional and nonfunctional pituitary adenomas, Rathke cleft cysts, clival chordomas, craniopharyngiomas, and arachnoid cysts. ${ }^{15}$

With accrued experience with EPS, the literature has focused on quality of life (QOL) measures and how they are influenced by surgical techniques, medical comorbidities, and demographic factors. ${ }^{3,8-10,22,24,26,27}$ Among these studies, the utility of the nasoseptal flap has demonstrated mixed subjective and objective postoperative outcomes, with results ranging from no effect on olfaction to significantly worsened olfaction up to 6 months postoperatively. ${ }^{8,26,27}$ Additionally, the literature is scarce regarding QOL and the relationship to smoking history following EPS, with one study demonstrating that smoking is a significant predictor for lack of postoperative subjective improvement. ${ }^{9}$ The literature has primarily reported findings as they pertain to entire groups, which clinicians must then

ABBREVIATIONS BMI = body mass index; EPS = endoscopic pituitary surgery; ESS = endoscopic sinus surgery; LOESS = locally estimated scatterplot smoothing; QOL = quality of life; SNOT $=$ Sino-Nasal Outcome Test. 
use for decision-making at the individual level. As such, we aimed for a generalizable study design and statistical analysis that could provide information for specific patient populations based on age, sex, smoking status, concurrent septoplasty, and use of nasoseptal flap while considering random variability of self-reported symptoms during the postoperative period. In addition, our study examines the relationship between objective endoscopic findings and subjective postoperative reports in order to provide a comprehensive analysis to enhance its utility in the clinical setting.

The objectives of this study were to analyze the factors that influence subjective and objective evolution of healing in regard to QOL. Subjective outcomes data were collected from the 22-item Sino-Nasal Outcome Test (SNOT-22) and its rhinological subdomain, while objective outcomes were collected from preoperative and postoperative endoscopy scores.

\section{Methods}

The study was designed as a patient cohort study and was approved by the Institutional Review Board at Rush University Medical Center. Data were collected from two fellowship-trained rhinologists and two cranial-based neurosurgeons at a single tertiary care academic institution from January 2014 to December 2018. The inclusion criteria included all patients undergoing transnasal EPS with at least 90 days of postoperative follow-up $(n=109)$. Patients with less than 90 days of postoperative follow-up $(n=29)$ were excluded from the study. Patient data collected included demographics, tumor characteristics, and surgical technique. Smokers were separated as prior smokers, currents smokers, or never smokers.

SNOT-22 questionnaire responses were collected at baseline prior to surgery and up to 52 weeks at each postoperative visit. The questionnaires were then classified by their rhinological subdomain (need to blow nose, sneezing, runny nose, postnasal discharge, thick nasal discharge, sense of smell/taste, blockage/congestion of nose). Responses to each question were recorded on a 6-item Likert scale ranging from 0 to 5 ( 0 being no problem and 5 being the problem is at its worst).

Data from preoperative and postoperative endoscopic examinations up to 52 weeks postoperatively were collected and subsequently scored on a binary scale ( 0 for absent finding; 1 for present finding) for the following examination categories: polyp, edema, crusting, discharge, and scarring. The cumulative score per patient is based on the presence or absence of each of the mentioned categories above, with scores ranging from 0 to 5 . This method of scoring is adopted from Chaudhry et al. ${ }^{4}$ The primary outcome measure of this study was the change in postoperative SNOT-22 score and return to baseline endoscopic score.

\section{Surgical Technique}

All surgical cases were performed by one of two rhinologists (P.S.B. and B.A.T.) in conjunction with neurosurgery. Transnasal image-guided access was achieved using a $0^{\circ}$ endoscope. Septal deviation or septal spur obstructing the operative field was managed with formal septoplasty or isolated spur resection, if clinically warranted. Middle turbinates were generally lateralized to achieve access to the sphenoethmoid recess and sphenoid sinuses; middle turbinate resection was performed in only select cases. Bilateral wide sphenoidotomies were performed, and posterior septectomy was completed to facilitate a binostril approach. A left rescue flap was performed in all cases with select conversion to full nasoseptal flap as dictated by intraoperative findings. The nasoseptal flap was limited to mucosa of the septum extending variably past the middle turbinate based on the extent of the defect and robustness of the leak. Extension to the nasal floor or lateral nasal wall was not required in any cases. An extended sphenoid approach was achieved by wide removal of the sphenoid rostrum with high-speed burr. Tumor resection was then performed by neurosurgery utilizing a 4-handed approach. Sellar reconstruction was achieved using absorbable packing and tissue glue in cases without CSF leakage. Formal sellar reconstruction was performed with a nasoseptal flap and absorbable packing, along with abdominal fat graft in select cases, for management of intraoperative CSF leaks. Otherwise, sellar reconstruction was performed using dural sealant and oxidized cellulose. In this study, all pituitary lesions were intrasellar and were accessed via a transsphenoidal approach. Other approaches, such as transtuberculum, transclival, transplanum, and transcribriform, were not performed in this study.

All patients were typically placed on a 1-week course of broad-spectrum postoperative antibiotics. Saline sprays were initiated after discharge from the hospital and saline irrigations were started 2-3 times daily after the first postoperative visit in 1 week. Formal debridement of the surgical cavity was performed 3-4 weeks postoperatively in all cases with or without a leak, followed by serial debridement monthly as dictated by clinical examination.

\section{Statistical Analysis}

All statistical analyses were conducted in $\mathrm{R}$ version 3.5.2 (R Foundation for Statistical Computing). Linear mixed-effects models were fitted with the lme4 package; $p$ values for models using the Satterthwaite approximation for degrees of freedom were computed with the lmerTest package. Linear mixed-effects models were used to evaluate postoperative trends in SNOT-22 total and SNOT-22 rhinological domains. The model for SNOT-22 total scores included a subject-level random intercept and a random slope for time (weeks) after operation. For the SNOT-22 rhinological subdomain, only a random intercept was used to improve model convergence. The mixedeffects models for longitudinal data estimated the SNOT22 score immediately after operation (intercept) and rate of change over time (interaction with time). Candidate fixed effects included main effects and interactions with time for the presence of prior sinonasal surgery, use of a nasoseptal flap, and tumor functioning status. Each candidate fixed effect was analyzed in a model that included either the main effect only or the main effect and time interaction, the random effects, and the time-fixed effect. If the candidate main effect was significant without the time interaction, it would be retained for the full model; if 
TABLE 1. Key cohort characteristics

\begin{tabular}{|c|c|}
\hline Characteristic & Value \\
\hline Total no. of patients & 109 \\
\hline Mean age at surgery (range), yrs & $53.72(16-82)$ \\
\hline Female (\%) & $59(54.1)$ \\
\hline Mean BMI (range) & $30.22(19-51)$ \\
\hline Prior smoker (\%) & $28(25.7)$ \\
\hline Current smoker (\%) & $7(6.4)$ \\
\hline \multicolumn{2}{|l|}{ Comorbidities (\%)* } \\
\hline 0 & $42(38.5)$ \\
\hline 1 & $37(33.9)$ \\
\hline $2+$ & $30(27.5)$ \\
\hline Prior chemotherapy (\%) & $3(2.8)$ \\
\hline Prior radiation $(\%)$ & $1(0.9)$ \\
\hline Postoperative chemotherapy (\%) & $3(2.8)$ \\
\hline Postoperative radiation (\%) & $6(5.5)$ \\
\hline Functioning tumors (\%) & $33(30.9)$ \\
\hline Nonfunctioning tumors (\%) & $75(68.8)$ \\
\hline Surgical technique & $20(18.3)$ \\
\hline Transsphenoidal approach & $109(100)$ \\
\hline Septoplasty & $24(22)$ \\
\hline Nasoseptal flap & $20(18.3)$ \\
\hline Polypectomy & $3(2.8)$ \\
\hline Septal spur resection & $21(19.3)$ \\
\hline Inferior turbinate submucous resection & $2(1.8)$ \\
\hline Synechiae lysis & $3(2.8)$ \\
\hline Middle turbinate resection & $4(3.7)$ \\
\hline SNOT-22 total mean time to baseline (SD), wks & $8.39(10.68)$ \\
\hline SNOT-22 rhinological mean time to baseline (SD), wks & $8.89(9.14)$ \\
\hline
\end{tabular}

* Comorbid conditions include diabetes, hypertension, heart failure, chronic kidney disease, liver disease, chronic obstructive pulmonary disease, and stroke.

the interaction with time was significant, both the main effect and time interaction were included. Main effects were included for age, sex, and smoking history in final models regardless of significance.

To analyze the endoscopic score, a Cox proportional hazards model was used. The event was defined to be the first postoperative visit where an endoscopic score of 0 was achieved. If an endoscopic score of 0 was not achieved, then the patients were considered to be censored at their last follow-up visit. A hazard ratio greater than 1 in this case indicates a greater recovery rate. Similar to the SNOT-22 models, the candidate covariates were included in the final model if they reached univariate significance, while age, sex, and smoking status were included regardless of significance. A p value $<0.05$ was considered to be significant for all analyses.

\section{Results}

The mean age of the 109 patients was 53.7 years (range 16-82 years) and $59(54.1 \%)$ of the patients were female. Within this sample, 35 patients $(32.1 \%)$ identified as either
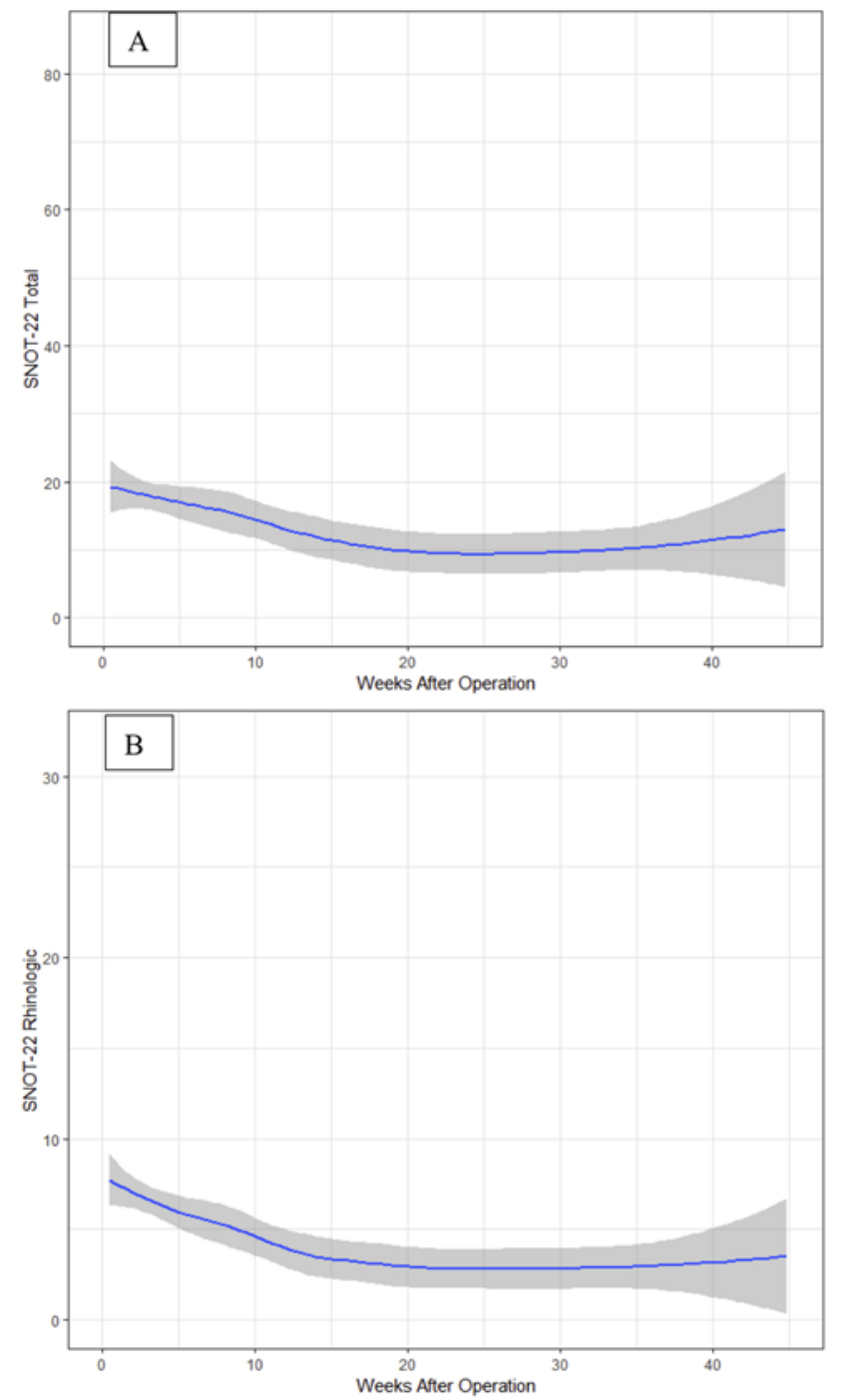

FIG. 1. LOESS curve of SNOT-22 total (A) and rhinological (B) scores following surgery.

current smokers $(n=7)$ or prior smokers $(n=28)$. The average body mass index (BMI) was $30.22 \mathrm{~kg} / \mathrm{m}^{2}$ (range $19-51 \mathrm{~kg} / \mathrm{m}^{2}$ ). The total number of patients with one or more comorbidities (diabetes, hypertension, heart failure, chronic kidney disease, liver disease, chronic obstructive pulmonary disease, stroke) was 67 (61.5\%). Key cohort characteristics are depicted in Table 1. A graphical depiction of the return-to-baseline SNOT scores following surgery is shown in Fig. 1.

Sellar pathology showed 96 macroadenomas (88.1\%), 7 microadenomas (6.4\%), 2 metastatic masses (1.8\%), and 4 unspecified masses (3.7\%). Tumor characteristics included 75 nonfunctional $(68.8 \%), 14$ growth hormone-secreting (12.8\%), 10 adrenocorticotropic hormone-secreting $(9.2 \%), 6$ prolactin-secreting $(5.5 \%), 1$ thyroid-stimulating hormone-secreting $(0.9 \%), 1$ follicle-stimulating hormone-secreting $(0.9 \%), 1$ multihormone-secreting $(0.9 \%)$, and 1 unknown $(0.9 \%)$ tumor.

Additional surgical interventions included septoplasty 
TABLE 2. Multivariate analysis of postoperative SNOT-22 total scores

\begin{tabular}{lrrrr}
\hline \multirow{2}{*}{ Variable } & & \multirow{2}{c}{$95 \% \mathrm{Cl}$} \\
\cline { 4 - 5 } & Estimate & $\mathrm{p}$ Value & \multicolumn{1}{c}{ Min } & Max \\
\hline Intercept & 18.2003 & $<0.01$ & 8.2401 & 28.1391 \\
\hline Age & -0.1480 & 0.08 & -0.3159 & 0.02050 \\
\hline Current smoker & 2.9310 & 0.53 & -6.1941 & 12.0164 \\
\hline Prior smoker & 11.1102 & $<0.01$ & 5.8258 & 16.3908 \\
\hline Female & 4.4017 & 0.05 & -0.0758 & 8.8787 \\
\hline Nasoseptal flap & 7.1191 & 0.01 & 1.6295 & 12.6012 \\
\hline Time after surgery & -0.5170 & $<0.01$ & -0.7942 & -0.2481 \\
(weeks) & & & & \\
\hline $\begin{array}{l}\text { Time after surgery } \\
\text { (weeks) } \times \text { age }\end{array}$ & 0.0055 & 0.03 & 0.0007 & 0.0103 \\
\hline
\end{tabular}

in $24(22 \%)$, nasoseptal flap in $20(18.3 \%)$, isolated septal spur resection in $4(3.7 \%)$, middle turbinate resection in $4(3.7 \%)$, synechiae lysis in $3(2.8 \%)$, polypectomy in $3(2.8 \%)$, and inferior turbinate submucous resection in 2 $(1.8 \%)$ patients. Of the 109 patients, $9(8.3 \%)$ presented for emergency surgery. Intraoperatively, 20 patients (18.3\%) had evidence of a CSF leak. Postoperative complications included CSF leak in $2(1.8 \%)$, transient diabetes insipidus in $22(20.2 \%)$, permanent diabetes insipidus in $4(3.7 \%)$, transient adenohypophyseal hormone deficiency in 16 (14.7\%), and permanent adenohypophyseal hormone deficiency in $4(3.7 \%)$ patients. The median length of stay in the hospital postoperatively was 4 days (range 2-60 days). The median postoperative follow-up was 271 days. The median number of postoperative visits was 5 (range 2-12 visits), with the first follow-up visit at a median of 8 days (range 3-211 days).

\section{SNOT-22 Total Data}

Univariate analysis of SNOT-22 total scores demonstrated significant contributions from a few key factors. Smoking status was associated with a worse postoperative SNOT-22 score following surgery ( $p<0.01 ; 95 \%$ CI $3.12-12.72$ ), though the rate of change of SNOT-22 score was not significantly impacted ( $\mathrm{p}=0.88 ; 95 \% \mathrm{CI}-0.17$ to 0.19 ). Similarly, patients requiring a nasoseptal flap had worse initial postoperative scores $(\mathrm{p}=0.02 ; 95 \%$ CI 1.08-12.76) without an impact on the rate of change of subsequent SNOT-22 scores ( $\mathrm{p}=0.2 ; 95 \% \mathrm{CI}-0.36$ to $0.07)$. Age was the only variable with a significant negative impact on the rate of change of SNOT-22 scores $(\mathrm{p}=$ $0.03 ; 95 \%$ CI $0-0.01)$.

In a multivariate analysis, prior smoking $(\mathrm{p}<0.01 ; 95 \%$ CI 5.82-16.39) and use of a nasoseptal flap ( $\mathrm{p}=0.01 ; 95 \%$ CI 1.62-12.60) were significant impactors on the evolution of healing (Table 2). Locally estimated scatterplot smoothing (LOESS) curves of SNOT-22 total scores following surgery in patients with and without nasoseptal flap use and patients with a history of smoking are depicted in Figs. 2A and 3A, respectively. The mean time to SNOT-22 total return to preoperative baseline score was 8.39 weeks (SD 10.68 weeks).

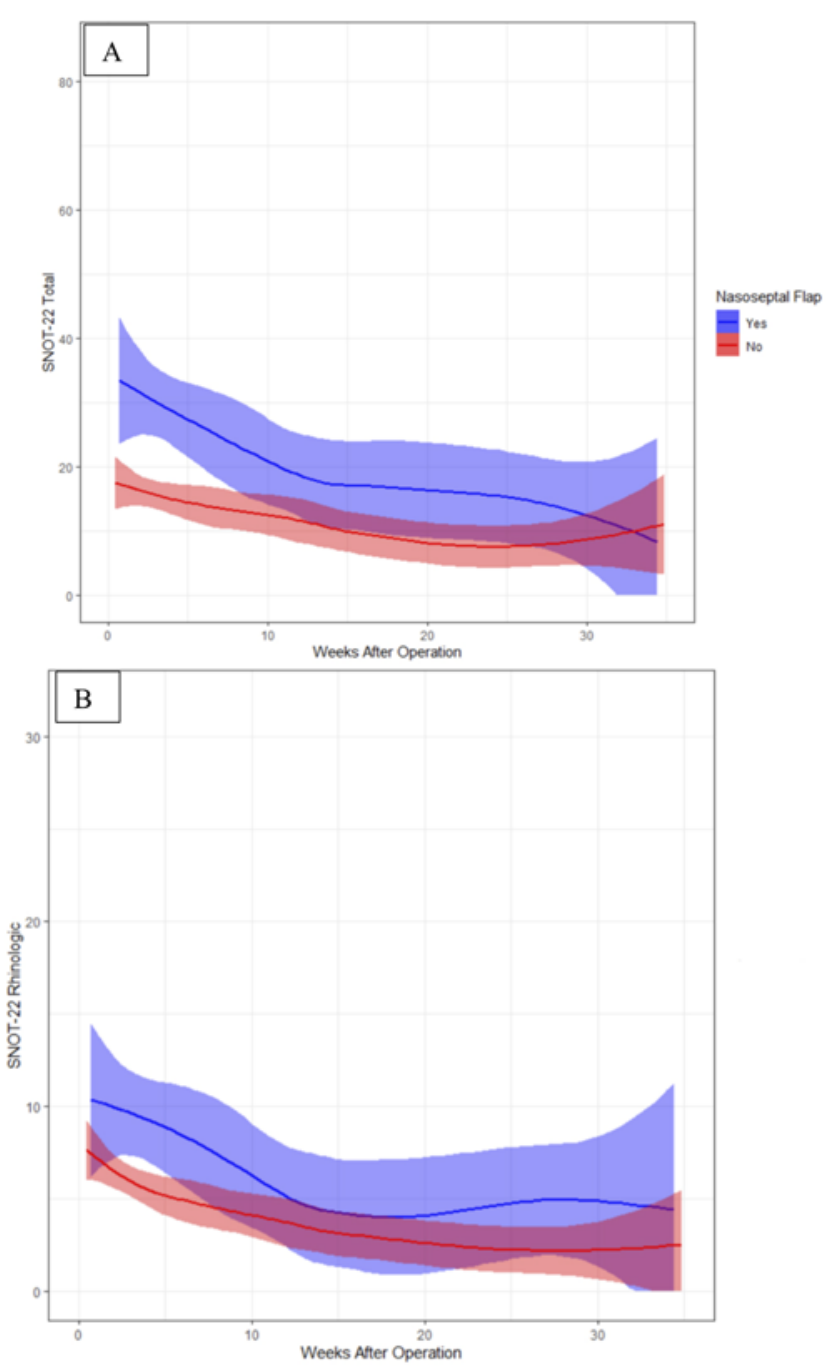

FIG. 2. LOESS curve of SNOT-22 total (A) and rhinological (B) scores following surgery for patients with and without nasoseptal flap use.

Secondary analysis of sex, BMI, preexisting comorbidities, prior sinonasal surgery, and concurrent septoplasty did not reveal significant contributions to the evolution of healing trends.

\section{SNOT-22 Rhinological Subdomain Data}

Univariate analysis of SNOT-22 rhinological subdomain data revealed that smoking status led to a worse initial postoperative SNOT-22 score $(\mathrm{p}=0.02 ; 95 \%$ CI $0.29-3.52$ ), though the rate of change was not significantly impacted ( $\mathrm{p}=0.9 ; 95 \% \mathrm{CI}-0.07$ to 0.06$)$. Paralleling this trend, patients requiring a nasoseptal flap had worse initial postoperative scores ( $\mathrm{p}=0.03$; 95\% CI 0.19-3.95) without significant contribution to the overall rate of change $(\mathrm{p}=$ $0.65 ; 95 \% \mathrm{CI}-0.10$ to 0.06 ).

Multivariate analysis that SNOT-22 rhinological scores were significantly impacted by age $(\mathrm{p}=0.01 ; 95 \% \mathrm{CI}$ -0.12 to -0.01 ), female sex ( $\mathrm{p}=0.02 ; 95 \%$ CI $0.28-3.46$ ), prior smoking ( $\mathrm{p}<0.01 ; 95 \%$ CI 1.38-5.09), and use of a 


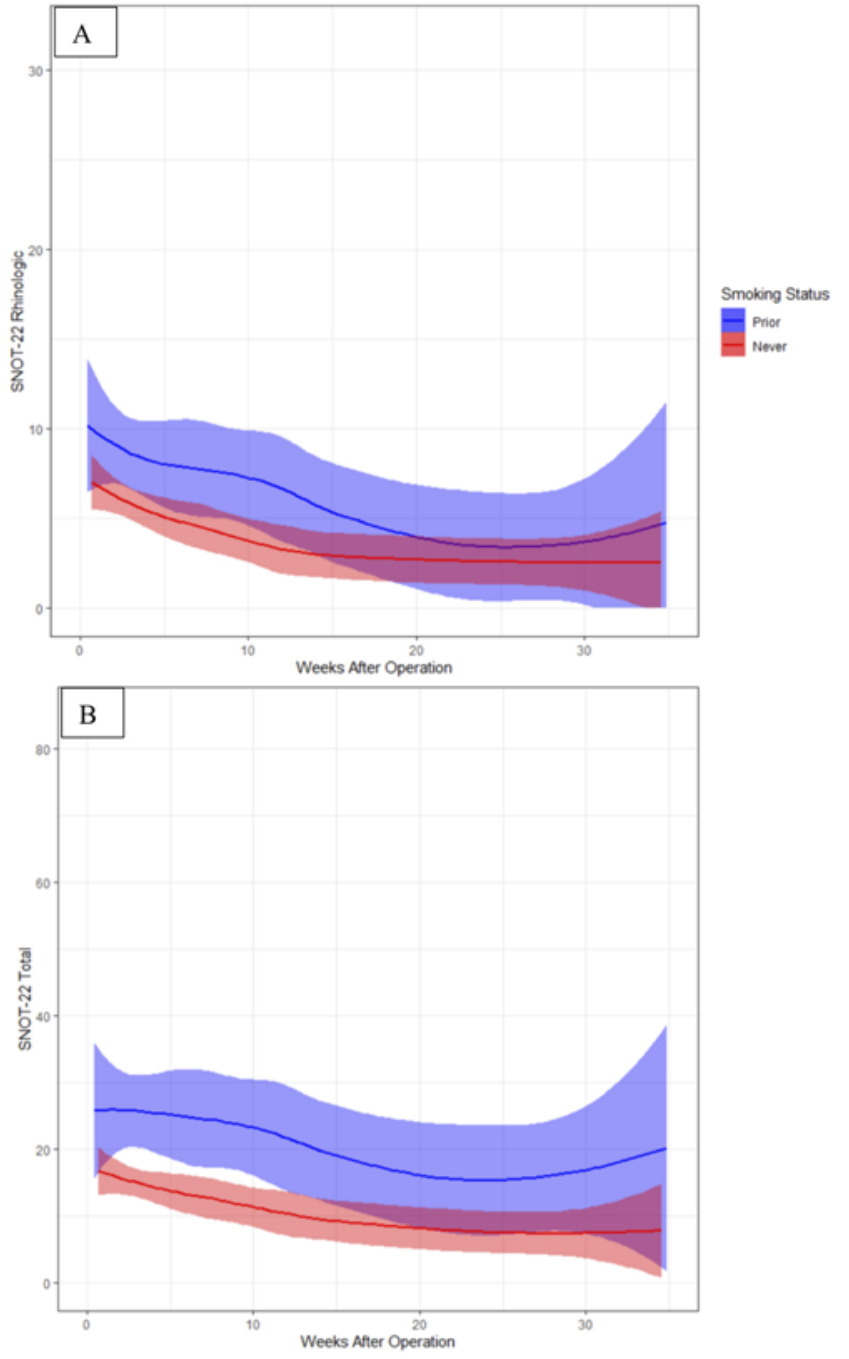

FIG. 3. LOESS curve of SNOT-22 total (A) and rhinological (B) scores following surgery for patients with and without a history of smoking.

nasoseptal flap ( $\mathrm{p}=0.02$; 95\% CI 0.42-4.30) (Table 3). LOESS curves of SNOT-22 rhinological scores following surgery in patients with and without nasoseptal flap use and patients with a history of smoking are depicted in Figs. 2B and 3B, respectively. The mean time to SNOT-22 rhinological return to preoperative baseline score was 8.89 weeks (SD 9.14 weeks).

Secondary analysis of BMI, preexisting comorbidities, prior sinonasal surgery, functioning tumors, and septoplasty revealed no significant contributions to evolution of healing trends.

\section{Endoscopic Examination Data}

SNOT-22 total and rhinological scores were separately compared with postoperative endoscopy scores. Baseline endoscopic scores prior to surgery were a median of 0 (range 0-3). Postoperative endoscopic scores minus the baseline score for the first 6 visits can be seen in Table 4 . Additionally, the endoscopic score was found to be cor-
TABLE 3. Multivariate analysis of postoperative SNOT-22 rhinologic subdomain scores

\begin{tabular}{lrrrr}
\hline & & & \multicolumn{2}{c}{$\begin{array}{c}95 \text { Confidence } \\
\text { Interval }\end{array}$} \\
\cline { 3 - 5 } \multicolumn{1}{c}{ Variable } & Estimate & p Value & \multicolumn{1}{c}{ Min } & Max \\
\hline Intercept & 7.7046 & $<0.01$ & 4.5093 & 10.8965 \\
\hline Age & -0.0706 & 0.01 & -0.1237 & -0.0176 \\
\hline Current smoker & 0.7465 & 0.66 & -2.5928 & 4.0828 \\
\hline Prior smoker & 3.2392 & $<0.01$ & 1.3849 & 5.0994 \\
\hline Female & 1.8765 & 0.02 & 0.2883 & 3.4682 \\
\hline Nasoseptal flap & 2.3593 & 0.02 & 0.4226 & 4.3026 \\
\hline $\begin{array}{l}\text { Time after surgery } \\
\text { (weeks) }\end{array}$ & -0.1970 & $<0.01$ & -0.2920 & -0.1020 \\
\hline $\begin{array}{l}\text { Time after surgery } \\
\text { (weeks) } \times \text { age }\end{array}$ & 0.0018 & 0.04 & 0.0001 & 0.0034 \\
\hline
\end{tabular}

related with SNOT-22 total score (Spearman's rho $=0.11$, $\mathrm{p}=0.01$ ), as well as with the SNOT-22 rhinological score (Spearman's rho $=0.16, \mathrm{p}<0.01$ ).

Analysis of age, smoking status, sex, prior sinonasal surgery, functioning tumors, nasoseptal flap use, BMI, septoplasty, and comorbidities revealed no significant contributions to evolution of healing as evident by endoscopy. Variable analysis of endoscopic examination can be found in Table 5.

\section{Discussion}

This study was conducted to better understand the factors that influence healing time and QOL among patients undergoing EPS. QOL was measured by the use of prospectively collected SNOT-22 scores and the rhinological subdomain of SNOT-22, which has been well validated and widely used in symptom assessment. ${ }^{7}$ We also aimed to examine endoscopic scores using the method from Chaudhry et al., since their article better depicted key examination findings following EPS than the traditional Lund-Kennedy nasal endoscopy scoring system. ${ }^{4}$ Additionally, the endoscopic scores provided objective findings that facilitated correlation with subjective QOL measures.

The results showed that patients requiring a nasoseptal flap started off with worse postoperative SNOT-22 total

TABLE 4. Postoperative endoscopic score per visit minus baseline endoscopic score

\begin{tabular}{cccc}
\hline $\begin{array}{c}\text { Visit No. (median } \\
\text { postop day) }\end{array}$ & $\begin{array}{c}\text { No. of } \\
\text { Patients }\end{array}$ & $\begin{array}{c}\text { Median Visit Score/ } \\
\text { Baseline Score (IQR) }\end{array}$ & $\begin{array}{c}\mathrm{p} \\
\text { Value }\end{array}$ \\
\hline $1(8)$ & 108 & $1(0,1)$ & $<0.01$ \\
\hline $2(22)$ & 109 & $1(1,2)$ & $<0.01$ \\
\hline $3(50)$ & 106 & $1(0,2)$ & $<0.01$ \\
\hline $4(101)$ & 97 & $1(0,1)$ & $<0.01$ \\
\hline $5(157)$ & 80 & $0(0,1)$ & $<0.01$ \\
\hline $6(241)$ & 51 & $0(0,1)$ & 0.04 \\
\hline
\end{tabular}


TABLE 5. Univariate hazard ratios for return to baseline endoscopic score

\begin{tabular}{llccc}
\hline \multirow{2}{*}{ Variable } & \multirow{2}{*}{$\begin{array}{c}\text { Hazard } \\
\text { Ratio }\end{array}$} & $\begin{array}{c}\mathrm{p} \\
\text { Value }\end{array}$ & \multicolumn{2}{c}{$95 \% \mathrm{Cl}$} \\
\cline { 4 - 5 } & & & Min & Max \\
\hline Age & 0.0996 & 0.6 & -0.0160 & 0.0093 \\
\hline Current smoker & 0.604 & 0.33 & -1.5221 & 0.5130 \\
\hline Prior smoker & 1.037 & 0.89 & -0.4669 & 0.5398 \\
\hline Female & 1.093 & 0.68 & -0.3444 & 0.5231 \\
\hline Prior sinonasal surgery & 0.883 & 0.67 & -0.6992 & 0.4523 \\
\hline Nasoseptal flap & 0.87 & 0.11 & -0.7150 & 0.4381 \\
\hline BMl & 0.969 & 0.63 & -0.0699 & 0.0074 \\
\hline 1 comorbidity & 0.855 & 0.55 & -0.6693 & 0.3573 \\
\hline 2+ comorbidities & 0.816 & 0.45 & -0.7415 & 0.3353 \\
\hline Septoplasty & 1.143 & 0.6 & -0.3708 & 0.6392 \\
\hline Functioning tumor & 0.896 & 0.65 & -0.5828 & 0.3627 \\
\hline
\end{tabular}

and rhinological subdomain scores $(\mathrm{p}=0.01$ and $\mathrm{p}=0.02$, respectively) than those who did not require a nasoseptal flap, but had no influence on the change of postoperative SNOT scores over time $(p=0.88$ and $p=0.65$, respectively). Given the fact that EPS has been shown to cause significant disruption to the sinonasal mucosa, there has been a strong interest in identifying and modifying surgical maneuvers that might disrupt surrounding structures during surgery. ${ }^{6,22,24}$ Sowerby et al. reported that there was no difference in preoperative versus postoperative olfaction scores in patients undergoing EPS with the unilateral middle turbinate-sacrificing approach. ${ }^{24}$ Rotenberg et al. showed that routine elevation of a flap with middle turbinate preservation led to a $16 \%$ decrease on the Smell Identification Test. ${ }^{22}$ In another study focusing on nasoseptal flap elevation during EPS, Harvey et al. utilized an olfactory strip preservation approach and showed that SNOT22 scores improved following surgery. ${ }^{10} \mathrm{McCoul}$ et al. prospectively quantified the degree of nasal patency among patients undergoing nasoseptal flap harvest and showed that there was no change postoperatively, thus giving an objective parameter to QOL.18

Overall, our findings agree with other studies that, although the use of a nasoseptal flap may lead to worse sinonasal morbidity in the immediate postoperative period, the use of a nasoseptal flap does not have a long-term negative impact on QOL and patients typically returned to baseline status by approximately 6 months after surgery. ${ }^{17,18,20}$ Furthermore, although we did not quantify the extent of sinonasal exposure (i.e., large sphenoidotomies, posterior ethmoidectomies), the use of a nasoseptal flap in our series typically acted as a surrogate marker for larger tumors requiring more sinonasal manipulation and thus more disturbance of the sinonasal cavity. One variable that may have better detailed the effect of raising a nasoseptal flap on sinonasal QOL would be the length of time in surgery; as such, we recommend that future studies on this topic include this factor. Another explanation that may warrant further examination is the use of absorbable packing during sellar reconstruction, which has been shown to nega- tively correlate with early sinonasal QOL following EPS. ${ }^{14}$ As such, the use of absorbable packing in patients requiring a nasoseptal flap may have been a cofounding variable in our cohort.

Septoplasty as an adjunct to EPS has been rarely studied in the context of QOL. In our study, septoplasty did not contribute to the rate of change in postoperative SNOT-22 scores and is similar to what has been previously reported. Lee et al. examined patients undergoing EPS with septoplasty and compared their pre- and postoperative SNOT22 scores and found there was no difference in the rhinological subdomain; instead, they found that overall QOL improved, as evidenced by a significant improvement in the sleep and psychological subdomains starting at 3 months postoperatively..$^{13}$ McCoul et al. showed that septoplasty did not worsen or improve baseline QOL scores following EPS. ${ }^{18}$ In contrast to EPS, endoscopic sinus surgery (ESS) with concurrent septoplasty has been reported in the literature and provides some context as to the effect of endoscopic septoplasty on QOL. For example, a prospective study by Scangas et al. showed that septoplasty during ESS for refractory chronic rhinosinusitis was not associated with QOL improvement postoperatively. ${ }^{23}$ To our knowledge, only one study has examined the utility of septoplasty during EPS; the authors favored the binostril 4-handed technique and lateralization of the turbinates in cases of narrow nasal passages and opted for posterior septectomy if needed. ${ }^{12}$

BMI in our cohort did not affect the rate of postoperative healing time as evidenced by SNOT-22 and endoscopic scores. Patel et al. prospectively examined QOL using SNOT-22 scores following TSS for craniopharyngiomas and found that higher BMI values were associated with a worse postoperative score, though the authors did not mention at what time point the scores were recorded or if the subjects' scores returned to their baseline. ${ }^{21}$ Steele et al. also prospectively examined the role of BMI on QOL in patients with refractory chronic rhinosinusitis undergoing ESS; they reported that all BMI groups showed significant improvement in QOL following surgery, indicating a minimal influence of BMI on postoperative outcomes following ESS. ${ }^{25}$ Interestingly, patients in their study were found to have worse baseline endoscopy scores as BMI increased, which diverged from our findings.

To the best of our knowledge, this is the first study to date that analyzes individualized healing trends post-EPS. Important limitations of the analysis must be acknowledged. The variables of interest were designated based on clinical experience, but it may be important to consider the contribution of other variables that were not specifically studied. Data were collected via chart review at a single academic institution, which must be considered when interpreting these results; SNOT-22 data were collected from patients prospectively, and endoscopic scores were recorded accordingly to attenuate some of these concerns. Additionally, the low number of current smokers as opposed to prior smokers in our study only allowed us to make a meaningful analysis of individuals with a history of smoking. While it is intuitive that sinonasal outcomes of current smokers would be worse than those of former smokers, a future subanalysis of data from this group 
might help elucidate whether the amount of time since smoking cessation is related to sinonasal outcomes. Nevertheless, our findings are in agreement with other studies that concluded that a history of smoking contributes to worse sinonasal QOL outcomes following EPS.", Additionally, although it is known that BMI and hormone-producing pituitary adenomas are associated with obstructive sleep apnea, ${ }^{2}$ we did not account for this in our study, and thus the presence of obstructive sleep apnea may serve as a confounding variable in our postoperative QOL measures. Furthermore, our investigation raises the question of the role of neuroendocrine outcomes and sinonasal QOL following EPS, which was recently explored in a cohort study following surgical patients with preoperative hypopituitarism versus those with only sinus disease. ${ }^{1}$ Future studies could analyze more cases and additional variables, preferably in a multicenter format, in order to minimize several of these limitations and unpack healing trends. Lastly, our use of SNOT-22 to collect QOL data is based on institutional standards. While we recognize the utility of using more specific QOL instruments such as the Anterior Skull Base Questionnaire, our review found that the scores of both questionnaires were inversely correlated (as expected given the scoring system) over time following endoscopic skull base surgery. ${ }^{16,17}$

\section{Conclusions}

Several important observations can be derived from the current analysis. Prior smokers and use of nasoseptal flap were associated with worse SNOT-22 total and rhinological scores, but these factors did not have any influence on healing time. Advanced age was not associated with a worse initial postoperative SNOT-22 total score but was associated with a worse initial SNOT-22 rhinological score; advanced age also showed a negative impact on SNOT-22 total score but not on the rhinological subdomain score. Female sex was initially correlated with a worse postoperative SNOT-22 rhinological score but had no effect on healing time. Last, BMI and septoplasty did not affect SNOT-22 scores or healing times. Endoscopic healing times were not associated with any of the factors studied.

\section{References}

1. Ajmal A, McKean E, Sullivan S, Barkan A: Decreased quality of life (QoL) in hypopituitary patients: involvement of glucocorticoid replacement and radiation therapy. Pituitary 21:624-630, 2018

2. Barbosa FR, Silva CM, Lima GA, Warszawski L, Domingues RC, Dominic M, et al: Prevalence of obstructive sleep apnea in patients with prolactinoma before and after treatment with dopamine agonists. Pituitary 17:441-449, 2014

3. Bedrosian JC, McCoul ED, Raithatha R, Akselrod OA, Anand VK, Schwartz TH: A prospective study of postoperative symptoms in sinonasal quality-of-life following endoscopic skull-base surgery: dissociations based on specific symptoms. Int Forum Allergy Rhinol 3:664-669, 2013

4. Chaudhry S, Chaudhry S, Qureshi T, Batra PS: Evolution of sinonasal symptoms and mucosal healing after minimally invasive pituitary surgery. Am J Rhinol Allergy 31:117-121, 2017

5. Derousseau T, Manjunath L, Harrow B, Zhang S, Batra PS:
Long-term changes in quality of life after endoscopic resection of sinonasal and skull-base tumors. Int Forum Allergy Rhinol 5:1129-1135, 2015

6. Dusick JR, Esposito F, Mattozo CA, Chaloner C, McArthur DL, Kelly DF: Endonasal transsphenoidal surgery: the patient's perspective-survey results from 259 patients. Surg Neurol 65:332-342, 2006

7. Feng AL, Wesely NC, Hoehle LP, Phillips KM, Yamasaki A, Campbell AP, et al: A validated model for the 22-item SinoNasal Outcome Test subdomain structure in chronic rhinosinusitis. Int Forum Allergy Rhinol 7:1140-1148, 2017

8. Hanson M, Patel PM, Betz C, Olson S, Panizza B, Wallwork B: Sinonasal outcomes following endoscopic anterior skull base surgery with nasoseptal flap reconstruction: a prospective study. J Laryngol Otol 129 (Suppl 3):S41-S46, 2015

9. Harrow BR, Batra PS: Sinonasal quality of life outcomes after minimally invasive resection of sinonasal and skull-base tumors. Int Forum Allergy Rhinol 3:1013-1020, 2013

10. Harvey RJ, Winder M, Davidson A, Steel T, Nalavenkata $\mathrm{S}$, Mrad N, et al: The olfactory strip and its preservation in endoscopic pituitary surgery maintains smell and sinonasal function. J Neurol Surg B Skull Base 76:464-470, 2015

11. Juraschka K, Khan OH, Godoy BL, Monsalves E, Kilian A, Krischek B, et al: Endoscopic endonasal transsphenoidal approach to large and giant pituitary adenomas: institutional experience and predictors of extent of resection. J Neurosurg 121:75-83, 2014

12. Kim DH, Hong YK, Jeun SS, Park JS, Kim SW, Cho JH, et al: Is septoplasty necessary when using the endoscopic endonasal transsphenoidal approach for a deviated nasal septum? J Neurol Surg B Skull Base 79:569-573, 2018

13. Lee DD, Peris-Celda M, Butrymowicz A, Kenning T, Pinheiro-Neto CD: Quality of life changes following concurrent septoplasty and/or inferior turbinoplasty during endoscopic pituitary surgery. World Neurosurg 98:303-307, 2017

14. Little AS, Kelly D, Milligan J, Griffiths C, Prevedello DM, Carrau RL, et al: Predictors of sinonasal quality of life and nasal morbidity after fully endoscopic transsphenoidal surgery. J Neurosurg 122:1458-1465, 2015

15. Louis RG, Eisenberg A, Barkhoudarian G, Griffiths C, Kelly DF: Evolution of minimally invasive approaches to the sella and parasellar region. Int Arch Otorhinolaryngol 18 (Suppl 2):S136-S148, 2014

16. McCoul ED, Anand VK, Bedrosian JC, Schwartz TH: Endoscopic skull base surgery and its impact on sinonasal-related quality of life. Int Forum Allergy Rhinol 2:174-181, 2012

17. McCoul ED, Anand VK, Schwartz TH: Improvements in site-specific quality of life 6 months after endoscopic anterior skull base surgery: a prospective study. J Neurosurg 117:498-506, 2012

18. McCoul ED, Patel AS, Bedrosian JC, Anand VK, Schwartz TH: Intranasal cross-sectional area and quality of life changes following endoscopic transsphenoidal skull base surgery. Int Forum Allergy Rhinol 5:1124-1128, 2015

19. Moussazadeh N, Prabhu V, Bander ED, Cusic RC, Tsiouris AJ, Anand VK, et al: Endoscopic endonasal versus open transcranial resection of craniopharyngiomas: a casematched single-institution analysis. Neurosurg Focus 41(6):E7, 2016

20. Pant H, Bhatki AM, Snyderman CH, Vescan AD, Carrau RL, Gardner P, et al: Quality of life following endonasal skull base surgery. Skull Base 20:35-40, 2010

21. Patel KS, Raza SM, McCoul ED, Patrona A, Greenfield JP, Souweidane MM, et al: Long-term quality of life after endonasal endoscopic resection of adult craniopharyngiomas. $\mathbf{J}$ Neurosurg 123:571-580, 2015

22. Rotenberg BW, Saunders S, Duggal N: Olfactory outcomes after endoscopic transsphenoidal pituitary surgery. Laryngoscope 121:1611-1613, 2011 
23. Scangas GA, Bleier BS, Husain Q, Holbrook EH, Gray ST, Metson R: Does bilateral inferior turbinate reduction affect long-term quality-of-life outcomes in patients undergoing endoscopic sinus surgery? Int Forum Allergy Rhinol 9:601-606, 2019

24. Sowerby LJ, Gross M, Broad R, Wright ED: Olfactory and sinonasal outcomes in endoscopic transsphenoidal skull-base surgery. Int Forum Allergy Rhinol 3:217-220, 2013

25. Steele TO, Mace JC, DeConde AS, Xiao CC, Storck KA, Gudis DA, et al: Does comorbid obesity impact quality of life outcomes in patients undergoing endoscopic sinus surgery? Int Forum Allergy Rhinol 5:1085-1094, 2015

26. Tam S, Duggal N, Rotenberg BW: Olfactory outcomes following endoscopic pituitary surgery with or without septal flap reconstruction: a randomized controlled trial. Int Forum Allergy Rhinol 3:62-65, 2013

27. Upadhyay S, Buohliqah L, Dolci RLL, Otto BA, Prevedello DM, Carrau RL: Periodic olfactory assessment in patients undergoing skull base surgery with preservation of the olfactory strip. Laryngoscope 127:1970-1975, 2017

\section{Disclosures}

B.A.T. has received a research grant from Advanced Rx. P.S.B. receives royalties from Springer.

\section{Author Contributions}

Conception and design: Batra, Shay, Beer-Furlan. Acquisition of data: Batra, Shay, Sturgis, Tajudeen. Analysis and interpretation of data: Batra, Shay, Sturgis, Ritz, Tajudeen. Drafting the article: Batra, Shay, Sturgis, Ritz, Tajudeen. Critically revising the article: all authors. Reviewed submitted version of manuscript: all authors. Statistical analysis: Batra, Shay, Sturgis, Ritz, Tajudeen. Administrative/technical/material support: Batra, Shay, Sturgis, Beer-Furlan, Muñoz, Byrne, Tajudeen. Study supervision: Batra, Shay, Beer-Furlan, Muñoz, Byrne, Tajudeen.

\section{Correspondence}

Pete S. Batra: Rush University Medical Center, Chicago, IL. pete_batra@rush.edu. 